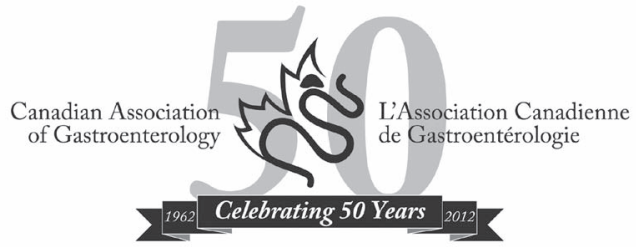

\title{
Canadian Association of Gastroenterology Awards presented at Canadian Digestive Diseases Week 2012
}

W e are delighted to announce the recipients of the 2012 prestigious Canadian Association of Gastroenterology (CAG) Awards, presented during Canadian Digestive Diseases Week (CDDW) 2012 in Montreal, Quebec:

\section{Research Excellence Award}

Dr Charles Bernstein, University of Manitoba

The Research Excellence Award is awarded to a member of the CAG who has made an outstanding contribution to gastroenterology through basic and/or clinical research.

\section{Education Excellence Award}

Dr Connie Switzer, University of Alberta

The CAG Education Excellence Award is awarded to a member of the CAG who has made an outstanding contribution to education on a national or international basis. The contribution may be in the areas of direct teaching, research in education or development of educational programs.

\section{Young Investigator Award}

Dr Elena Verdu, McMaster University

The Young Investigator Award is awarded to a member of the CAG and recognizes outstanding contributions to gastroenterology through basic and/or clinical research by a young investigator.

\section{Young Educator Award}

Dr Clarence Wong, University of Alberta

The CAG Young Educator Award is awarded to a CAG member and recognizes outstanding contributions to gastroenterology through education by a young investigator.

\section{Visiting Research Professor}

Dr Nicola Jones, University of Toronto

The CAG Visiting Research Professorship is awarded annually to a member of CAG who is a proven teacher and an outstanding researcher.

\section{Visiting Clinical Professor}

\section{Dr David Armstrong, McMaster University}

The CAG Visiting Clinical Professorship, introduced in 2012, is offered annually to a member of CAG who is a proven educator and an outstanding clinician with interest in clinical research.

\author{
Distinguished Service Award \\ Dr Desmond Leddin, Dalhousie University, and \\ Dr Pierre Paré, Université Laval
}

This award is to honour individuals who have provided distinguished service to the CAG.

McKenna Lecturer Award

Dr Richard Hunt, McMaster University

Dr Richard D McKenna was an outstanding clinician, scientist and humanitarian whose enthusiasm and knowledge drove the establishment of the CAG. To honour him, the CAG each year selects an individual who has made significant contributions to gastrointestinal medicine and/or science to give the Richard D McKenna Memorial Lecture. This award is the highest honour the CAG bestows. The lecture is the highlight of the opening of CDDW.

\section{AWARDS NOMINATIONS}

Nominations for the above awards can be made by any member of the CAG by completing and submitting on-line, the fillable PDF nomination form found on the CAG web site at www.cag-acg.org (under 'Research', 'CAG Research Awards' or 'Physician Education', 'Awards') or by sending the completed form and supporting documentation, by fax or e-mail to the CAG National Office:

\section{CAG National Office \\ 1540 Cornwall Road, Suite 224 \\ Oakville, ON L6J 7W5 \\ Fax: 905-829-0242 \\ E-mail: cagoffice@cag-acg.org}

Descriptions of the awards, complete eligibility criteria and the process for nominating candidates may be found on the CAG website at www.cag-acg.org. Simply enter the name of the award in the 'Search' box of the website and click 'go'.

For all nominations, a copy of the candidate's curriculum vitae must be forwarded along with the nomination and it is encouraged to provide a letter of support.

The CAG Research and Education Committees will review the nominations and make recommendations to the Board, who will make the final decision regarding recipients. Selection will be based on the research or education record of candidates.

The deadline for receipt of nominations is July 31, 2012.

The CAG is proud to acknowledge its Benefactor Corporate Sponsors:

Abbott Canada

Pentax Canada Inc
AstraZeneca Canada Inc

Janssen Inc
Olympus Canada Inc

Takeda Canada Inc 


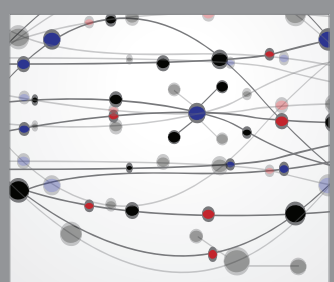

The Scientific World Journal
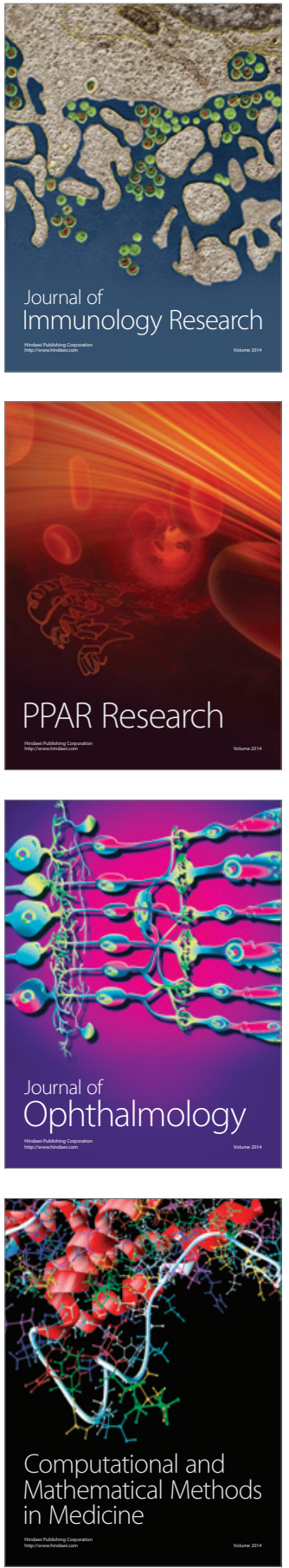

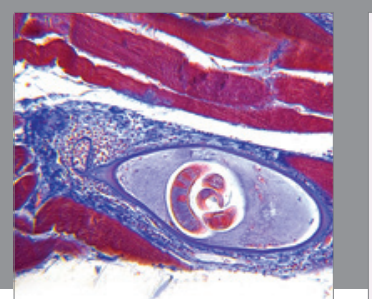

Gastroenterology Research and Practice

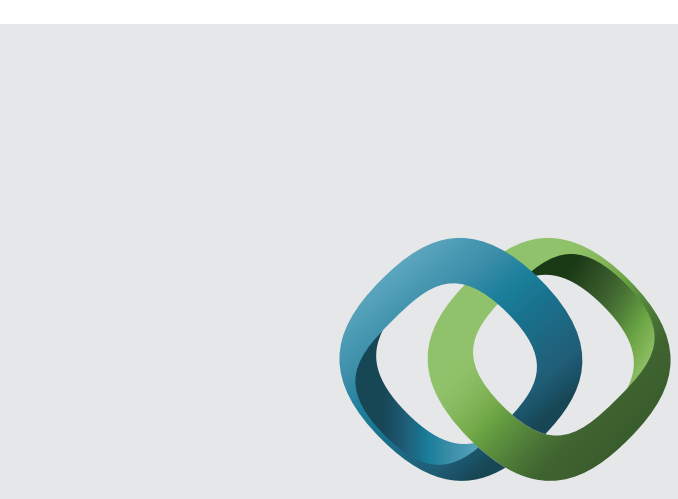

\section{Hindawi}

Submit your manuscripts at

http://www.hindawi.com
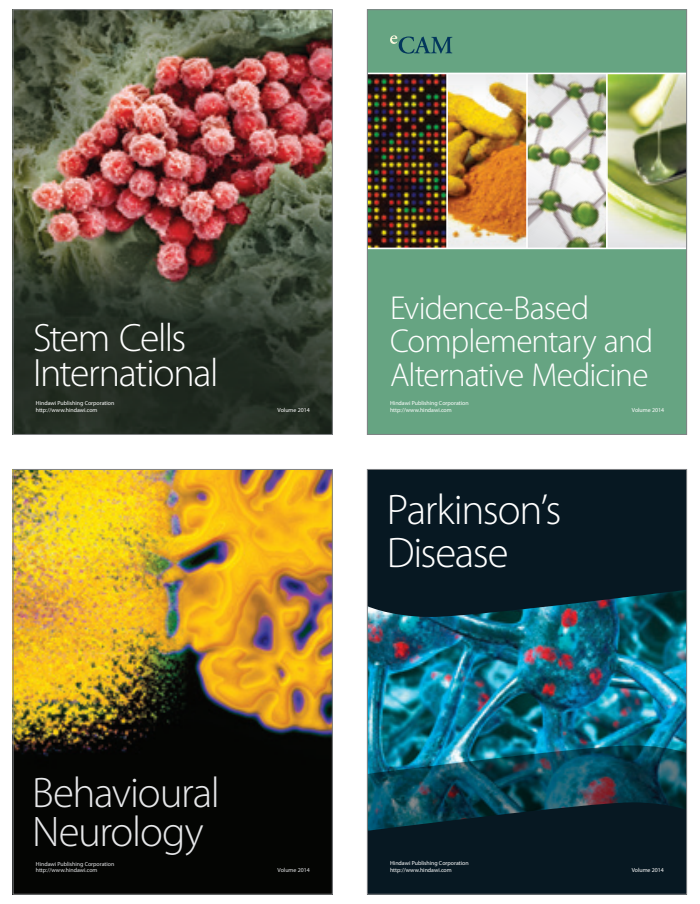
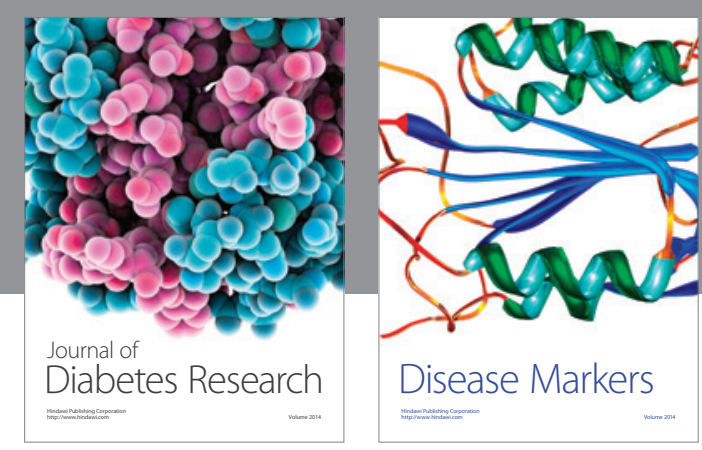

Disease Markers
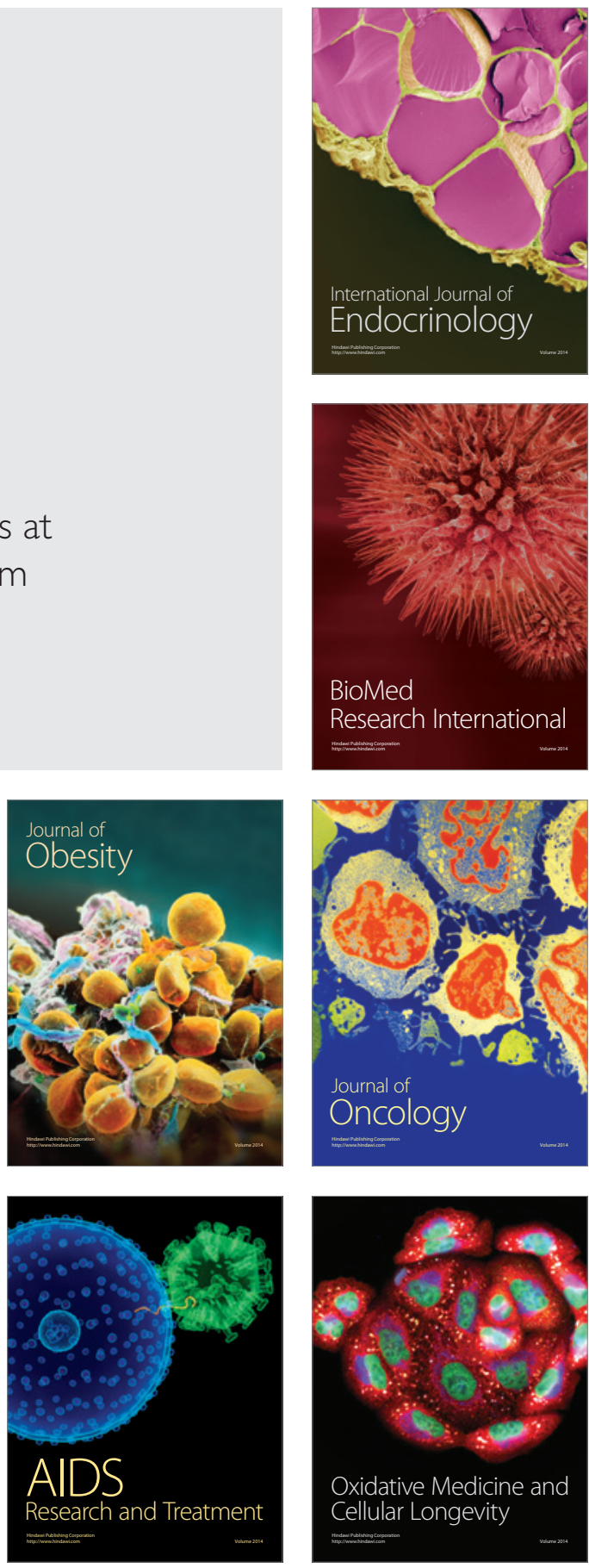